San Jose State University

SJSU ScholarWorks

$5-1-2005$

\title{
The Relationship Between Student Perceptions of Faculty Support and Student Perceptions of Clinical Competency
}

Linda Clark

San Jose State University

Follow this and additional works at: https://scholarworks.sjsu.edu/etd_projects

Part of the Other Nursing Commons

\section{Recommended Citation}

Clark, Linda, "The Relationship Between Student Perceptions of Faculty Support and Student Perceptions of Clinical Competency" (2005). Master's Projects. 753.

DOI: https://doi.org/10.31979/etd.dshv-b5e8

https://scholarworks.sjsu.edu/etd_projects/753

This Master's Project is brought to you for free and open access by the Master's Theses and Graduate Research at SJSU ScholarWorks. It has been accepted for inclusion in Master's Projects by an authorized administrator of SJSU ScholarWorks. For more information, please contact scholarworks@sjsu.edu. 


\section{SAN JOSE STATE UNIVERSITY \\ SCHOOL OF NURSING}

\section{MASTER'S PROGRAM PROJECT OPTION (PLAN B) PROJECT SIGNATURE FORM}

STUDENT NAME Linda Clork

SEMESTER ENROLLED Spring 2005

TITLE OF PROJECT The Relationship Betwees

Student Perceptions of Facult, Suppert and Student Percertions of Clinical

Competenc f.

NAME OF JOURNAL Jownal of Nursing Education

The project and manuscript have been successfully completed and meet the standards of the School of Nursing at San Jose State University. The project demonstrates the application of professional knowledge, clinical expertise, and scholarly thinking. An abstract of the project and two copies of the manuscript are attached.
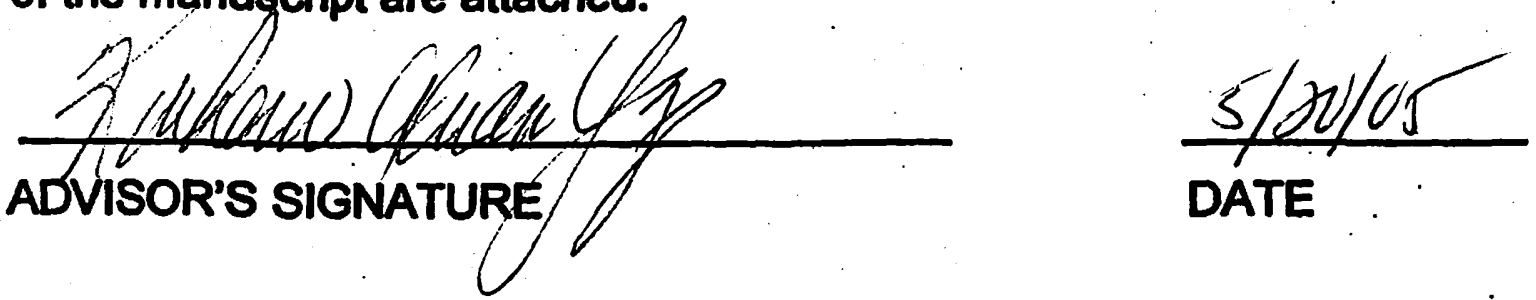

DATE

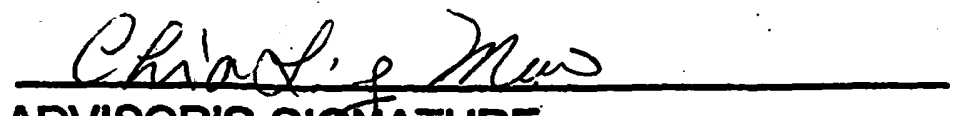

ADVISOR'S SIGATATURE

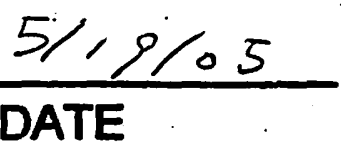

Please submit this form to the Graduate Coordinator. Attach abstract, two copies of the manuscript, and documentation of submission to the journal (i.e., postal receipt). 
The Relationship Between Student Perceptions of Faculty Support

and

Student Perceptions of Clinical Competency

\author{
A Research Project \\ Presented to the Faculty of the School of Nursing \\ San Jose State University
}

In Partial Fulfillment

of the Requirements for

the Degree of Master of Science

\author{
By \\ Linda Clark
}

May 2005 


\begin{abstract}
This study explored the relationship between student perceptions of faculty support and student perceptions of clinical competency in beginning and senior level nursing students. A total of 91 ethnically diverse, generic baccalaureate nursing students from a state funded university participated in the study. The participants completed Mozingo, Thomas, and Brooks' (1995) Perceived Competency Scale (PCS), Shelton's (2003) Perceived Faculty Support Scales (PFSS), and a demographic questionnaire.

An independent $t$ test determined that the observed mean difference between perceived competency scores in 46 beginning students $(M=32.02)$ and 45 senior students $(M=27.36)$ was statistically significant $(t(89)=3.25, p<.05)$. The students demonstrated high scores of perceived faculty support and demonstrated no difference between the beginning $(M=94.82)$ and the senior $(\mathrm{M}=95.61)$ nursing students $(t(87)=-.25, p>.05)$. No statistically significant correlation was found between student perceptions of faculty support and their perceptions of clinical competency $(r=.20, p>.05)$ in both groups. However, this study identified faculty behaviors that were perceived to enhance student achievement.
\end{abstract}


The Relationship between Student Perceptions of Faculty Support

and Student Perceptions of Clinical Competency

Introduction

Caring is the essence of nursing. Scotto (2003) describes a scenario of a nurse demonstrating caring by intellectually, psychologically, spiritually, and physically looking after a patient. Scotto (2003) writes that in education it is not enough to impart the words of caring; the educator must provide the experiences of how to care. As the need for more nurses in the workforce increases, it is essential that nurse educators have the necessary skills to guide the next generation in the art of caring not only for others but also for themselves. Tanner (2005) summarizes the urgency of meeting this need by emphasizing that there is little evidence of research about strategies to improve the science of clinical teaching and adds, "...the relationship between teacher and student and the quality of their interaction is supremely important in learning outcome" (p. 161).

Balancing the needs for nursing educators to produce competent nursing professionals and the obligation to nurture and care for students dates back to the first nursing theorist, Florence Nightingale. Nightingale (1850) wrote, "Now no more childish things, no more vain things, no more love, no more marriage. Now, Lord let me think only of thy will, what Thou willest me to do" (as cited in Dunphy, 2001, p. 34). Rather than harboring such a harsh, self-sacrificing outlook on nursing, today's educators must conduct research into the efficacy of creating a more caring approach to educating and mentoring future nurses (Tanner, 2005; Wade, 2004; Clark, Owen \& Tholcken 2003; Birx \& Baldwin, 2002; Secrest, Norwood, \& Keatley, 2003; Shelton, 2003; Brandon, 1998; Mozingo, Thomas, \& Brooks, 1995; Haldordottir, 1990). Increasing the number of competent nursing graduates is critical to meeting the global needs of humanity. 
The United States Department of Health and Human Services (USDHHS) (2002) writes that by 2020 the nursing workforce is projected to increase by $6 \%$, while the demand is projected to increase by $40 \%$. These projected figures reflect a nursing shortage of $34 \%$. Additionally, the nursing workforce is aging with a projected $128 \%$ loss of nurses by 2020 (USDHHS, 2002). To add to the situation, the number of individuals graduating as licensed nurses is predicted to decrease 17\% (USDHHS, 2002). Between 2010 and 2030, the population of people age 65 and older is predicted to more than double in the United States (Institute for the Future, 2003). This increase in people over age 65 will intensify the demand on the healthcare system due to chronic healthcare needs specific to this population.

\section{Purpose of the Study}

The purpose of this study was to examine the relationship between student perceptions of faculty support and student perceptions of clinical competency in beginning and senior nursing students. The research analyzed beginning and senior nursing students' perceptions of clinical competency in a generic, baccalaureate program.

\section{Theoretical Framework}

The theoretical framework for this research study was Watson's Theory of Caring (1979; 2000) and Bandura's (1997) Theory of Self-Efficacy. Bandura's (1997) Theory of Self-Efficacy describes faculty caring as integral to the creation of an environment that fosters clinical competency. Watson (1989) writes that there is a distinct link between nursing students' clinical competency and the caring attitudes of faculty.

Faculty support (instructor caring) is linked to Watson's (1979) carative factor of "promotion of transpersonal teaching-learning" (p. 9). Wade's (2004) study also linked these two components. Transpersonal teaching is a creation of a caring climate or culture in which the student feels inspired to obtain the knowledge or transpersonal knowing (Watson, 2002). 
Transpersonal knowing is based on the connection to humanity and creating a conscious movement towards the intention of understanding, accepting, healing, and caring as a spiritual journey or quest (Watson, 2002). It is the intention of the educator to act as the facilitator, inspiring the student by communicating and modeling a passion for being an integral part of the caring practice.

Perceived clinical competence is linked with Watson's $(2000, \uparrow 1)$ carative factor relating to the use of a "creative problem-solving caring process". Wade's (2004) study also linked these two components. This carative factor describes the application and use of knowledge, clinical expertise, ability to see beyond the situation, and the use of the nursing process to achieve the outcome at the appropriate time. Simply stated, this is a caring consciousness. This factor is associated with the knowledge and competence to provide caring moments from a humanistic holistic approach centered on the individual, without preconceived notions from the caregiver's perspective. Wade (2004) interpreted this caring factor as perceived clinical competence and added that Watson $(1979 ; 2000)$ did not distinguish between clinical competence and perceived clinical competence in the creation of the carative factor.

Bandura's (1997) Theory of Self-Efficacy fosters the belief that student nurses' perceptions of competency guide the success of their professional nursing practice. In other words, students with high perceptions of clinical competency set high goals and strive to perform to the best of their abilities in challenging situations. Whereas, nursing students with low perceptions of clinical competency are more likely to feel defeated and give up in challenging situations. According to Bandura (1997), increased levels of faculty support (instructor caring) will provide students with the foundation to achieve their goals.

Bandura's Theory of Self-Efficacy (1997) emerged from Bandura's Social Learning Theory (1977). Bandura's Theory of Self-Efficacy describes the concept of the influences that yield 
individuals the confidence to believe they can perform skills and have the ability to persist in overcoming obstacles. The intrinsic and extrinsic influences that affect self-efficacy are cognitive, behavior, and environment (Bandura, 1997). In other words, nursing students will achieve higher levels of self-efficacy through choosing to apply themselves by mastering theoretical information, applying knowledge and skills towards clinical competency, learning through faculty mentoring and modeling, maintaining a positive physiological state, and an attitude that their goal can be accomplished. Bandura (1997) writes, "Unless people believe they can produce desired effects by their actions, they have little incentive to act" (pp. 2-3). According to Bandura's Theory of Self-Efficacy (1997), the faculty role is to provide a foundation for nursing students to grow and foster confidence within the educational environment.

\section{Literature Review}

An extensive search of the literature ranging 1980 to 2005 , using the key words competency, caring, faculty support, student retention, professional socialization, self-efficacy, and nursing students revealed much discussion on how to impart professional socialization and caring in education. Haldordottir (1990) wrote that students responded with feelings of self-worth and motivation toward personal and professional growth when they felt appreciated and cared for by faculty that modeled the behaviors they were teaching. Brandon (1998) writes that compassion towards others and self-awareness are integral for all healing professions. Secrest et al. (2003) in their existential-phenomenological study, uncovered the patterns of knowing, belonging, and affirmation that were related to baccalaureate nursing students' feelings of professionalism.

Ellis (1980) found in a pilot study with 177 baccalaureate nursing students that self-esteem and self-confidence diminished with each year of nursing education. Ellis wrote (1980) that the more contact the students had with the faculty the less positive they felt about themselves. This 
research is contrary to other findings in the review of the literature. There is need for further research in this area.

Mozingo et al. (1995) conducted a quantitative and qualitative study with 204 nursing students within two weeks of graduation with the Perceived Competency Scale (PCS) that was developed by Mozingo and Thomas. Mozingo et al. (1995) found 75\% of students felt they needed increased time in the clinical setting and increased exposure to clinical skills. Additionally, $78 \%$ of the students were able to identify a faculty mentor and $57.4 \%$ reported feeling anxious about their clinical skills.

Clark et al. (2004) developed a tool to measure 80 baccalaureate nursing students' perceptions of clinical competence in a chronic care case management course. The purpose of the instrument was to assist faculty in evaluating student perceptions about the curriculum content and evaluate student's self-efficacy in performing clinical skills (Clark et al., 2004). Clark et al. (2004) reported that in order for students to succeed they needed to feel the content or skill was meaningful. This was the first instrument developed to measure nursing students' perceptions of clinical competency in 14 years and was limited to the chronic care setting.

Birx and Baldwin (2002) conducted a formative evaluation of methods of promoting nurturing staff-student relationships. Positive nurturing relationships between students and staff were enhanced by a unit-based orientation; evaluation about encounters with staff; and collaborative relationships between faculty, students, administration and staff (Birx \& Baldwin, 2002). Birx and Baldwin (2002) concluded that the concept of caring needs to be extended toward students to cultivate the knowledge, skills, and values of professional development.

Shelton (2003) conducted a cross-sectional study of 458 associate degree nursing students exploring their perceptions of faculty support and student retention using the Shelton Model of Student Retention as the conceptual framework which was based on Bandura's Theory of Self- 
Efficacy and Tinto's Theory of Student Retention. Shelton (2003) developed the Perceived Faculty Support Scale (PFSS) to look at factors that improved perceptions of psychological and functional support. Shelton (2003) demonstrated “...that both psychological and functional support contribute to student retention by promoting student persistence" (p. 75).

One study has explored the relationship of nursing students' perceptions of faculty support and their perceptions of clinical competency. Wade (1999) conducted a concept analysis that defined the attributes associated with professional nurse autonomy as nurturing relationships with clients, making responsible decisions, maintaining a reciprocal collegial relationship, and acting as a client advocate. Wade (2004) reported that caring and autonomy through perceived clinical competence are necessary components in achieving student success. Wade (2004) developed an instrument for this study to measure perceptions of instructor caring behaviors, and used a second instrument to measure autonomy. Males were excluded from the study population. Wade's (2004) research was unique in that the study linked student perceptions of faculty support with clinical competency.

\section{Research Questions}

1. What is the relationship between student perceptions of faculty support and student perceptions of clinical competency in beginning and senior nursing students enrolled in a baccalaureate nursing program?

2. Do student perceptions of clinical competency differ in beginning and senior nursing students enrolled in a baccalaureate nursing program?

Methodology

Sample/Demographics

A convenience sample of 91 nursing students from a state funded university participated in a non-experimental, cross-sectional, survey design study. The ethnically diverse, generic 
baccalaureate sample was comprised of 46 beginning nursing students enrolled in their first clinical experience and 45 senior nursing students in their final clinical experience. The participants were asked to complete the PCS (Table 1), PFSS (Table 2), and a demographic questionnaire. However, one female beginning and one female senior nursing student were dropped from the data analysis of PFSS because of incomplete information.

The sample contained 79 females and 12 males. The ethnic breakdown of the sample was $30 \%$ Filipino, $16 \%$ Caucasian, $16 \%$ Vietnamese, $9 \%$ Chinese, 9\% Latino/Hispanic, $5 \%$ African/African-American, 5\% Asian, $1 \%$ American Indian, $7 \%$ other, and $2 \%$ unreported. Thirty-three percent of the participants identified English as their second language. Procedure

Permission to conduct the study was obtained from the university formal internal review board, the school of nursing, and the participating beginning and senior level faculty. The researcher attended the beginning and senior-level nursing theory courses at the mid-point in the semester to obtain participants. The nursing students were given an information packet containing; (a) a cover letter introducing the researcher and explaining the purpose of the study; (b) a consent form explaining time required to complete the study instruments and insuring respondent anonymity; (c) PCS; (d) PFSS; (e) and a demographic questionnaire. To insure respondent anonymity, the consent forms and the questionnaires were separated and placed in sealed envelopes.

Instruments

The participants in this study were asked to complete two questionnaires. Permission was obtained for the use of the PCS which measured perceived clinical competency and the PFSS which measured perceived faculty support. The PCS consists of a 12 item questionnaire scored on a 5-point Likert scale ranging from strongly agree (1) to strongly disagree (5). The potential 
scores ranged from 12 to 60 with a mode of 36 . Three of the items were reverse scored. The reliability and validity of the PCS instrument was tested with a sample of 204 senior, baccalaureate level nursing students, after the initial use of the instrument the Cronbach's alpha coefficient was .83 (Mozingo et al., 1995).

The PFSS reflects the student perceptions of the psychological supportive behaviors (caring and listening) and the functional supportive behaviors (communicating objectives and giving feedback) that assist in student success. This instrument consists of a 24 item questionnaire scored on a 5-point Likert scale ranging from strongly agree (5) to strongly disagree (1). The PFSS potential scores ranged from 24 to 120 with a mode of 72 . The reliability and validity of the PFSS was tested with a sample of 458 associate level nursing students and the Cronbach's alpha coefficient was .92 (Shelton, 2003).

\section{Results}

\section{Perceived Clinical Competency}

The result of an independent $t$ test showed there was a significant difference between the groups $(t(89)=3.25, \mathrm{p}<.05)$. The beginning students $(\mathrm{M}=32.02, \mathrm{SD}=6.74)$ perceived themselves as less clinically competent than the senior $(M=27.36, S D=6.97)$ nursing students (Table 3$)$. Perceived Faculty Support

The result of an independent $t$ test showed there was no significant difference found between the groups $(t(87)=-.25, \mathrm{p}>.05)$. The beginning $(\mathrm{M}=94.82, \mathrm{SD}=16.22)$ and the senior students $(\mathrm{M}=95.61, \mathrm{SD}=14.10)$ results demonstrated a high perception of faculty support. Perceptions of Faculty Support and Clinical Competency

A correlation between student perceptions of faculty support and student perceptions of clinical competence was performed. The result using the Pearson product-moment correlation 
coefficient $(r),(r=-.20, \mathrm{p}>.05)$ was not statistically significant. The nursing students had similar levels of perceived faculty support and differing levels of clinical competency.

Discussion

\section{Perceived Competency}

In reviewing the PCS, $39 \%$ of the beginning and $84 \%$ of the senior nursing students agreed or strongly agreed that they had a faculty mentor. The value of faculty mentorship and modeling of behaviors are important to the promotion of self-efficacy in nursing students. The development of transpersonal teaching and knowing is contingent on developing a strong connection, or caring consciousness between faculty and student.

Seventy-four percent of the beginning and $67 \%$ of the senior nursing students agreed or strongly agreed that they had perceptions of anxiety regarding clinical skills. Additionally, 53\% of the senior nursing students agreed or strongly agreed that they were scared by the thought of their first nursing job. The perceptions of anxiety remain high in the senior students as they approached graduation and prepared to enter nursing practice without the safety net of the faculty. This phenomenon can be explained by the faculties' increased expectations of performance interdependence and the impending transition to professional practice. The ratio of students to senior-level clinical faculty is traditionally higher than at the beginning-level because senior nursing students are working with a preceptor in the clinical setting, rather than under the direct supervision of the clinical faculty and the staff nurse.

Sixty-one percent of the beginning and $60 \%$ of the senior nursing students agreed or strongly agreed that they were lacking technical skills. The small increase in perceptions of competency regarding deficits in technical skills from the beginning to senior nursing students may be explained by the increased level of functioning and responsibility as students advance through the program. The beginning nursing student is a novice with little understanding of the field of 
nursing and may not have a level of understanding to comprehend their inexperience at making clinical decisions and performing interventions to impact patient care (Benner, 1985). The senior nursing student is functioning at the advanced beginner level and has some understanding of the requirements of safe nursing performance and is practicing interdependence in the clinical setting (Benner, 1985). The enhanced performance expectations of senior nursing students might explain the small increase in perceptions of clinical competency in this group. Focusing on areas that nursing students perceive as lacking is an important step in increasing the transpersonal knowing and self-efficacy concepts.

The PCS items that scored highest by the beginning nursing students were: they had strengths to bring to nursing, well identified professional goals, felt prepared to practice safe care, and perceived that the teachers respected their abilities. These findings suggest that faculty demonstrated respect and trust in the students promoting increased feelings of self-efficacy, refuting Ellis's (1980) finding that the more contact that nursing students had with faculty the less positive they felt about themselves.

The senior nursing students PCS items that were ranked highest were: they had strengths to bring to nursing, well identified goals, at least one faculty mentor, and knew where to find the answers to clinical questions. The findings suggest that the majority of the senior students had a mentor and increased levels of self-efficacy regarding goals, strengths, and ability to search for information independently.

Perceived Faculty Support

In reviewing the PFSS items, only $55 \%$ of the senior and $57 \%$ of beginning nursing students agreed or strongly agreed that faculty were aware of the level of student comprehension regarding important nursing concepts. Additionally, only $64 \%$ of the seniors and $47 \%$ of the beginning nursing students agreed or strongly agreed that faculty assessed the level of student 
needs and tailored the teaching strategies to meet the deficits. The findings suggest that faculty need to create an atmosphere of trust, encouraging students to ask questions and tailor learning needs accordingly. Shelton (2003) pointed out that it is important for faculty to take the first step, approaching students who are struggling, demonstrating that the intention of faculty is promoting student success.

Although there were no significant differences between the groups, the PFSS items that were scored highest by the beginning nursing students were that faculty encouraged students to ask questions, demonstrated respect, were good role models, and were approachable. These results demonstrate the importance of creating a strong student/teacher relationship early in a nursing program to develop a supportive, environment for enhancing student achievement.

The PFSS items that were ranked highest by senior nursing students were that faculty trusted students , encouraged questions, were open to difference points of views, acknowledged when students performed well, provided helpful feedback, were good role models and had a genuine interest in students. These findings suggested that the faculty were valued as mentors who created an atmosphere of trust and professional acknowledgement.

It is interesting to note that the overall group PFSS items that ranked highest in an ethnically diverse, generic baccalaureate program are that faculty:

- Encourage students to ask questions.

- Stress important concepts.

- Can be trusted.

- Are good role models for students.

These items offer insight into the themes of faculty support that are perceived to enhance student achievement. 
Limitations

The ability to generalize the findings is limited by the use of a self-selected convenience sample and a cross-sectional design. Additional limitations were a sample selection from one university, small sample size, and a lack of a pre-test/post-test to assess baseline and end-point anxiety levels.

\section{Recommendations}

If the nursing shortage continues to increase, a healthcare catastrophe will unfold. The profession of nursing needs to welcome and embrace the new graduates in order to maintain the workforce necessary to care for the population of the United States. Thus, faculty must provide the experiences needed for nursing students to enter the work force with feelings of confidence. Tang, Chou, and Chiang (2005) found, "It is a teacher's attitude toward students, rather than the teacher's professional ability, that is the crucial factor in whether the teacher is effective or ineffective" (p. 191). Faculty must find strategies to cultivate the belief that student nurses with high perceptions of clinical competency will cope with the increasing demands and complexities of healthcare as they enter the arena and develop their own professional practice. Further research is needed to explore effective strategies to nurture confidence in nursing students and tools to evaluate nursing student perceptions of confidence and faculty support.

Areas that were identified for faculty development by promoting self-efficacy and a caring environment for educating nursing students are:

- Creating early formalized mentoring programs.

- Developing methods for providing feedback.

- Promoting trust and opportunities for questioning.

- Approaching students who are having difficulties and offering support. 
- Responding to students needs.

The caring influence of faculty will educate student nurses to care holistically for themselves, as well as their peers and clients. It is not enough to educate nursing students to think critically. Faculty must listen, develop trust, and create the opportunity for the "teaching moment" in which nursing students are allowed to reveal their perceptions of areas of incompetence without judgment. Then faculty can respond by providing opportunities to consolidate the nursing student's expertise, thus increasing transpersonal knowing and selfefficacy. These opportunities will help nursing students to develop a caring consciousness by giving them the confidence to apply their knowledge and expertise. Higher ratios of seniorlevel faculty to students may provide the support necessary to promote the use of the "creative problem-solving caring process" for the transition to the professional setting (Watson, 2000, ๆ 1).

\section{Conclusion}

This study demonstrated that nursing students felt supported by faculty. However, further research is needed to examine levels of anxiety identified by nursing students and to develop strategies for reducing anxiety while imparting baseline clinical knowledge. Faculty has made tremendous strides since Florence Nightingale (1850) commanded young women to sacrifice all for the art and science of nursing (as cited in Dunphy, 2001). Nurse educators have begun to compile evidence that supports a caring educational environment which provides students with the experience of how to care for themselves and others by developing tools, exploring student perceptions of clinical competency, and responding to student perceptions of need, rather than the faculties perceptions of need (Tanner, 2005; Wade, 2004; Clark, Owen \& Tholcken 2003; Birx \& Baldwin, 2002; Secrest, Norwood, \& Keatley, 2003; Shelton, 2003; Brandon, 1998; Mozingo, Thomas, \& Brooks, 1995; Haldordottir, 1990). The cultural shift from a self- 
sacrificing environment of servitude to an environment where nursing students feel supported and acknowledged will prepare the next generation of nurses to bring a caring, humanistic approach to today's complex, ever-changing world. 


\section{References}

Bandura, A. (1977). Social learning theory. New York: General Learning Press.

Bandura, A. (1997). Self-efficacy: The exercise of control. New York: W. H. Freeman.

Bevis, E. O. \& Watson, J. (1989). Toward a caring curriculum: A new pedagogy for nursing. New York: National League for Nursing.

Benner, P. (1985). From novice to expert. Reading, MA: Addison-Wesley.

Brandon, D. (1998). Zen healing. Journal of Interprofessional Care, 12, 407-410.

Birx, E., \& Baldwin, S. (2002). Nurturing staff-student relationships. Journal of Nursing Education, 4l(2), 86-88.

Dunphy, D. (2001). Florence Nightingale caring actualized: A legacy for nursing. In M. E. Parker (Ed.), Nursing theories and nursing practice (pp. 31-52). Philadelphia: F. A. Davis. Ellis, L. (1980). An investigation of nursing student self-concept levels: A pilot study. Nursing Research, 29, 369-390.

Halldorsdottir, S. (1990). Caring imperative in education. In M. Leininger \& J. Watson (Eds.), The essential structure of a caring and uncaring encounter with a teacher: The perspective of the nursing student (pp. 95-108). New York: National League for Nursing.

Institute for the Future (Ed.). (2003). Health and healthcare 2010: The forecast, the challenge (2nd ed.). Princeton, NJ: Jossey-Bass.

Clark, M. C., Owen, S. V., \& Tholcken, M. A. (2004). Measuring student perceptions of clinical competence. Journal of Nursing Education, 43, 548-554.

Mozingo, J., Thomas, S., \& Brooks, E. (1995). Factors associated with perceived competency levels of graduating seniors in a baccalaureate nursing program. Journal of Nursing Education, 34, 115-122.

Scotto, C. J. (2003). A new view of caring. Journal of Nursing Education, 42, 289-291. 
Secrest, J. A., Norwood, B. R., \& Keatley, V. M. (2003). "I was actually a nurse": The meaning of professionalism for baccalaureate nursing students. Journal of Nursing Education, 42, 77-83.

Shelton, E. N. (2003). Faculty support and student retention. Journal of Nursing Education, 42, $68-77$.

Tang, F., Chou, S., \& Chiang, H. (2005). Students' perceptions of effective and ineffective clinical instructors. Journal of Nursing Education, 44, 187-192.

Tanner, C. A. (2005). The art and science of clinical teaching. Journal of Nursing Education, 44, 151-152.

United States Department of Health and Human Services Bureau of Health Professions National Center for Health Workforce Analysis (2002). Projected supply, demand and shortages of registered nurses: 2000-2020. Washington DC: Health Resources and Services Administration.

Wade, G. H. (1999). Professional nurse autonomy; Concept analysis and application to nursing education. Journal of Advanced Nursing, 30, 310-318.

Wade, G. H. (2004). A model of the attitudinal component of professional nurse autonomy. Journal of Nursing Education, 42, 116-123.

Watson, J. (1979). The philosophy and science of caring. Boston: Little, Brown.

Watson, J. (2000). Theory of human caring. Retrieved March 13, 2004, from http://www2.uchc.edu/son/caring/content/wct.asp

Watson, J. (2002). Intentionality and caring-healing consciousness: A practice of transpersonal nursing. Holistic Nursing Practice, 16(4), 12-19. 
Table 1

Perceived Competency Scale with Ranking of the Differences in Nursing Student Mean Scores

\begin{tabular}{|l|l|l|l|l|}
\hline \multicolumn{1}{|c|}{ Items } & $\begin{array}{l}\text { Beginning } \\
\text { N=46 } \\
\text { Mean }\end{array}$ & $\begin{array}{l}\text { Senior } \\
\text { N=45 } \\
\text { Mean }\end{array}$ & $\begin{array}{l}\text { Difference } \\
\text { Rank of } \\
\text { the } \\
\text { Difference }\end{array}$ \\
\hline $\begin{array}{l}\text { 1. I have strengths that I will bring to my first } \\
\text { nursing position. }\end{array}$ & 1.89 & 1.64 & -0.25 & 8 \\
\hline 2. I have well-identified professional goals. & 1.91 & 1.71 & -0.20 & 10 \\
\hline 3. I have confidence in my abilities as a nurse. & 2.43 & 2.09 & -0.34 & 7 \\
\hline 4. I know how to give excellent nursing care. & 2.63 & 1.98 & -0.65 & 2 \\
\hline $\begin{array}{l}\text { 5. I am somewhat lacking in technical skills.* } \\
\text { 6. At least one faculty member has served as a } \\
\text { mentor to me. }\end{array}$ & 3.72 & 3.51 & -0.21 & 9 \\
\hline $\begin{array}{l}\text { 7. I feel that my program has prepared me to } \\
\text { be a safe practitioner. }\end{array}$ & 2.13 & 1.78 & -1.17 & 1 \\
\hline $\begin{array}{l}\text { 8. I am really scared when I think of my first } \\
\text { job.* }\end{array}$ & 3.48 & 3.33 & -0.38 & 5 \\
\hline $\begin{array}{l}\text { 9. I know how to find the answers to my } \\
\text { questions about nursing care. }\end{array}$ & 2.22 & 1.84 & -0.38 & 6 \\
\hline 10. My teachers respect my abilities. & 2.15 & 2.07 & -0.08 & 12 \\
\hline $\begin{array}{l}\text { 11. I know how to do a lot of things. } \\
\text { * Reverse-scored items }\end{array}$ & 2.67 & 2.04 & -0.63 & 3 \\
\hline
\end{tabular}

Reprinted with permission from Mozingo et al., 1995 
Table 2

Perceived Faculty Support Scale with Nursing Student Mean, Summation, and Rank Scores

\begin{tabular}{|c|c|c|c|c|}
\hline Items & $\begin{array}{l}\text { Beginning } \\
\mathrm{N}=46 \\
\text { Mean }\end{array}$ & $\begin{array}{l}\text { Senior } \\
\mathrm{N}=45 \\
\text { Mean }\end{array}$ & Summation & $\begin{array}{l}\text { Rank } \\
\text { Score }\end{array}$ \\
\hline 1. Know if students understand what is being taught. & 3.59 & 3.41 & 7.00 & 24 \\
\hline 2. Demonstrate respect for students. & 4.11 & 3.98 & 8.09 & 7 \\
\hline 3. Set challenging but attainable goals for students. & 4.00 & 4.02 & 8.02 & 10 \\
\hline 4. Acknowledge when students have done well. & 3.98 & 4.18 & 8.16 & $\overline{6}$ \\
\hline 5. Are helpful in new situations without taking over. & 3.83 & 3.98 & 7.81 & 19 \\
\hline 6. Stress important concepts. & 4.07 & 4.20 & 8.27 & 2 \\
\hline 7. Are approachable. & 4.09 & 4.07 & 8.16 & 5 \\
\hline 8. Correct students without belittling them. & 4.04 & 3.78 & 7.82 & 18 \\
\hline 9. Listen to students. & 3.96 & 4.0 & 7.96 & 14 \\
\hline 10. Can be trusted. & 4.04 & 4.22 & 8.26 & 3 \\
\hline 11. Provide helpful feedback on student assignments. & 3.78 & 4.09 & 7.87 & 17 \\
\hline 12. Are open to different points of view. & 3.96 & 3.78 & 7.74 & 21 \\
\hline 13. Encourage students to ask questions. & 4.26 & 4.18 & 8.44 & $\overline{1}$ \\
\hline 14. Provide help outside of class. & 3.59 & 3.84 & 7.43 & 22 \\
\hline 15. Vary teaching methods to meet student needs. & 3.57 & 3.58 & 7.15 & 23 \\
\hline 16. Make expectations clear. & 3.87 & 3.89 & 7.76 & 20 \\
\hline 17. Are patient with students. & 3.93 & 4.04 & 7.79 & 13 \\
\hline 18. Are good role models for students. & 4.09 & 4.09 & 8.18 & 4 \\
\hline 19. Are realistic in expectations. & 3.93 & 4.04 & 7.97 & 12 \\
\hline 20. Present information clearly. & 3.96 & 3.96 & 7.92 & 15 \\
\hline 21. Clarify information that is not understood. & 4.04 & 4.02 & 8.06 & 8 \\
\hline 22. Have a genuine interest in students. & 3.96 & 4.09 & 8.05 & 9 \\
\hline 23. Provide study guides and written materials. & 3.93 & 4.04 & 7.97 & 11 \\
\hline 24. Demonstrate confidence in students & 3.87 & 4.04 & 7.91 & 16 \\
\hline
\end{tabular}


Table 3

Results of t test Between Groups-Perceived Competency Scale and Perceived Faculty Support Scale

Scale

PERCEIVED COMPETENCY SCALE
Students $\mathbf{N}$ Mean : Std. Deviation

$\begin{array}{l:ll:}\text { Beginning }_{4} & 32.02 & 6.74\end{array}$

\begin{tabular}{ll|l|l} 
Senior & 45 & 27.36 & 6.97
\end{tabular}

\begin{tabular}{ll|l|l} 
Beginning & 45 & 94.82 & 16.22
\end{tabular}

PERCEIVED FACULTY SUPPORT SCALE 